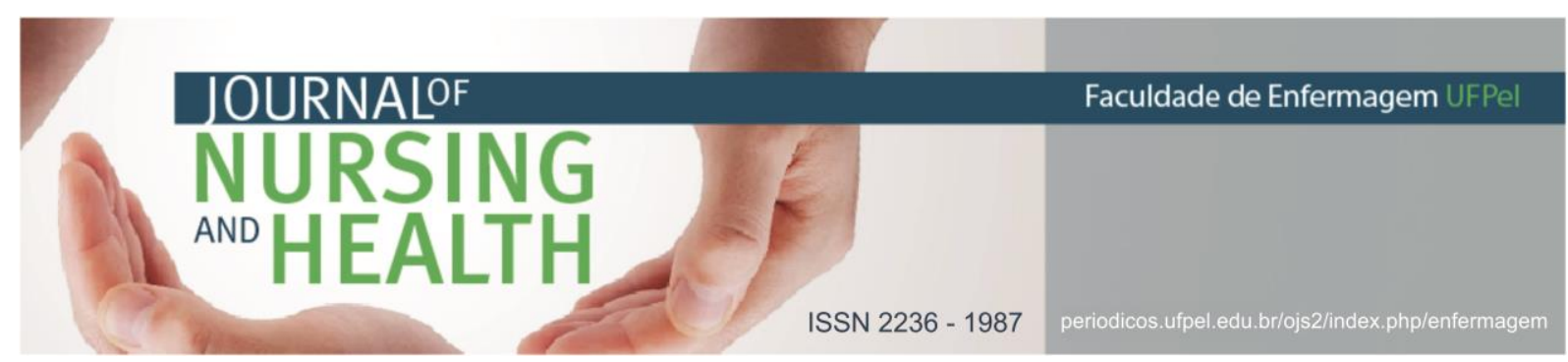

ENTREVISTA NARRATIVA

\title{
A experiência do movimento de ouvidores de vozes em Brasília/DF
}

\author{
The experience of the voice hearer's movement in Brasilia/DF
}

\section{La experiencia del movimiento de oyentes de voces en Brasilia/DF}

Willrich, Janaína Quinzen'; Pickersgill, Mirela Farias²; Portela, Dariane Lima³; Cruz, Márcio Santos da ${ }^{4}$

Como citar este artigo: Willrich, JQ, Pickersgill MF, Portela DL, Cruz MS. A experiência do movimento de ouvidores de vozes em Brasília/DF. J. nurs. health. 2018;8(n.esp.):e188428

Descritores: Saúde Mental; Enfermagem psiquiátrica; Narração.

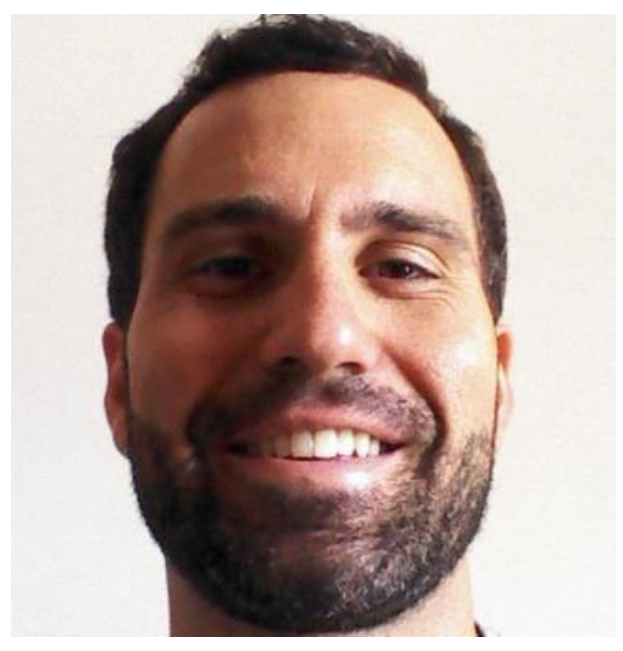

\section{APRESENTAÇÃO}

Henrique Campagnollo Dávila Fernandes é psicólogo. Teve ciência da abordagem da audição de vozes no ano de 2014, por meio de sua supervisora, Prof $^{\mathrm{a}} \mathrm{Dr}^{\mathrm{a}}$ Tania Inessa Martins de
Resende. Em 2015, ingressou no programa de mestrado da Universidade de Brasília, sob orientação da Prof. $\mathrm{Dr}^{\mathrm{a}}$ Valeska Zanello, com a proposta de trabalhar a referida abordagem, através de um grupo de ouvidores de vozes no Centro de Atenção Psicossocial (CAPS) onde fazia trabalho voluntário. Auxiliou na estruturação do Instituto Mãos Amigas, entidade que acolhe e acompanha pessoas em situação de sofrimento na comunidade da Ceilândia-DF, e que, dentre seus trabalhos, oferece suporte a ouvidores de vozes e seus familiares. Atualmente é professor das Faculdades Integradas da União Educacional do Planalto Central, e psicólogo do Programa Cuida Bem Servidor, vinculado à Medicina do Trabalho do Hospital das Forças Armadas.

\footnotetext{
1 Enfermeira. Doutora em Ciências da Saúde. Universidade Federal de Pelotas (UFPEL). E-mail: janainaqwill@yahoo.com.br http://orcid.org/0000-0001-7427-9305

2 Enfermeira. Especialista em Saúde Pública com ênfase em Saúde da Família. Universidade Federal de Pelotas (UFPEL). E-mail: mirelapick@hotmail.com http://orcid.org/0000-0002-4884-6668

${ }^{3}$ Enfermeira. Especialista em Estratégia em Saúde da Família com ênfase em políticas públicas. Universidade Federal de Pelotas (UFPEL). E-mail: dariane.lportela@hotmail.com http://orcid.org/0000-0003-1409-1823

${ }^{4}$ Assistente Social. Especialista em Saúde Mental e Coletiva. Universidade Federal de Pelotas (UFPEL). E-mail: marciocruz_sb@hotmail.com http://orcid.org/0000-0002-1651-946X
} 


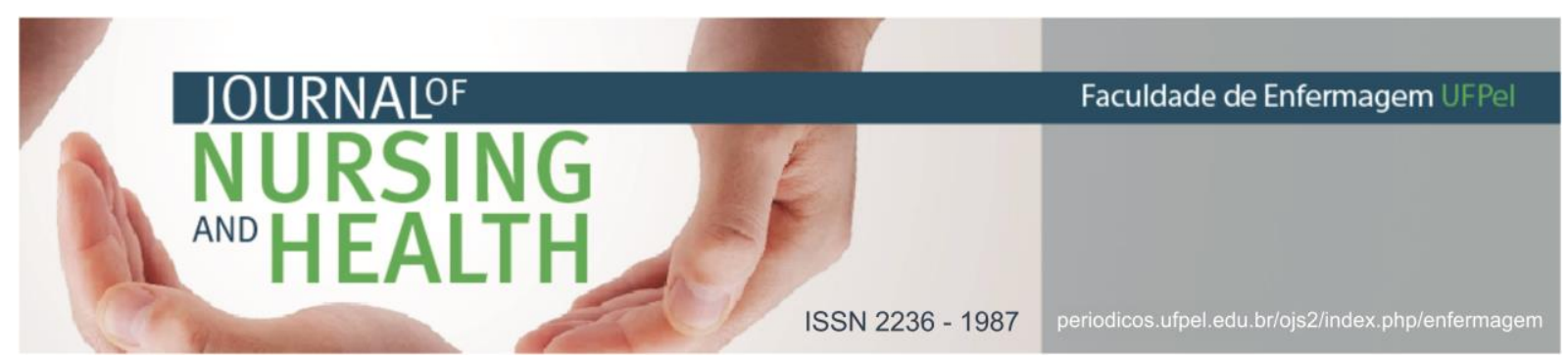

Aproximação pessoal e profissional com a experiência do movimento de ouvidores de vozes

Sou Henrique Campagnollo Dávila Fernandes, sou psicólogo entrei no Centro de Atenção Psicossocial (CAPS) como pesquisador em psicanálise, estudando Lacan. Porém, a realidade vivenciada no CAPS mostrou-se distante da teoria trazida no livro. Mesmo assim terminei a pesquisa, embora minha abordagem sempre estivesse mais pautada pela fenomenologia, de entrar em contato, de conversar com eles, de ver o que estava acontecendo e o que a gente podia fazer.

Em 2014 após a formatura em psicologia, continuei num grupo de pesquisa juntamente com a minha orientadora de estágio. Ela estava fazendo o doutoramento e nesse período foi para um congresso em Campinas, que contou com a presença do Paul Baker. Ela voltou desse congresso muito entusiasmada com o trabalho que estava se desenvolvendo na Inglaterra e se espalhando pelo mundo, e me disse que esse trabalho tinha muita aproximação com o que eu acreditava e com o que ela também acreditava, porque ela estava fazendo um doutorado em convivência.

Nesta época, fazíamos os grupos de pesquisa toda semana e conversávamos sobre tudo, inclusive, sobre as vozes. Eu tinha acabado de me formar e estava no CAPS fazendo treinamento em serviço, e buscava um caminho. Passei a estudar e em 2014 tive contato com a abordagem da International Hearing Voices Projects (INTERVOICE), e falei: "ah é uma possibilidade de eu fazer alguma coisa lá".

Então no início de 2015 eu apresentei um projeto para equipe e como eu estava no serviço há muito tempo, eles tinham muita confiança no meu trabalho e a gerente falou assim: "olha, o que você quiser fazer, vamos fazer".

O grupo: motivações, avanços, desafios...

Eu sempre tive muita curiosidade de trabalhar com a questão dos ouvidores de vozes, porque tinha uma demanda no CAPS de pessoas, que mesmo medicadas, continuavam ouvindo vozes. Então alguns relatavam não entender o uso da medicação, pois além de não cessar a audição das vozes ela trazia agravos como sonolência, diminuição da concentração e memória. Eles diziam: "depois que passei a usar medicação eu não consigo acordar, não consigo estudar, não consigo trabalhar, não consigo me relacionar com ninguém, e continuo ouvindo as vozes". Então essa questão passou a chamar minha atenção.

Na época em que propus iniciar o grupo de ouvidores de vozes, em todos grupos desenvolvidos no CAPS tinham pelo menos dois profissionais coordenando, mas como esse grupo que propus era muito diferente daquilo que até então era realizado a equipe recebeu com certo receio. Alguns profissionais 


\section{NURSING \\ AND

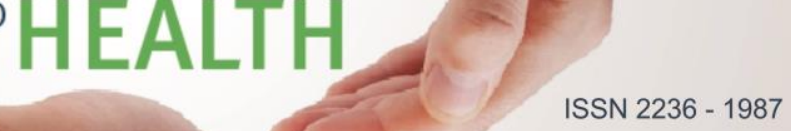

demonstraram dúvidas em relação aos resultados que o grupo produziria, pois não acreditavam ser possível conversar com as vozes uma vez que esta era uma "alucinação", algo que não fazia parte da minha realidade, não era real para mim. Ao falar que não fazia parte da minha realidade, quero evidenciar $o$ sentido de que um dos argumentos da equipe foi que eu conversaria com um ente não presente no mesmo espaço físico que o do ouvidor de vozes e que, portanto, o diálogo com as vozes seria um procedimento um tanto que "impalpável", por não se basear em um fenômeno evidente, e que por isso talvez não surtisse efeitos terapêuticos.

Então, apesar da equipe trabalhar muito bem e ter profissionais excelentes, tiveram, por exemplo, pessoas que não aceitaram iniciar o grupo comigo, por várias razões, inclusive por não terem interesse mesmo. Mesmo assim mantive a decisão de iniciar o grupo de ouvidores de vozes, num movimento de experimentação, mas orientado pelo material do Paul Baker.

Passamos a conduzir o grupo e a trabalhar temas que não haviam sido trabalhados, porque até então o foco de abordagem das vozes buscava sua remissão, pois segundo a lógica biomédica estas são consideradas como sintomas. ${ }^{1}$ Assim, os resultados positivos do grupo dizem respeito a essa nova abordagem e também pelo fato da maioria dos participantes do grupo não terem realizado consulta psiquiátrica e iniciado com medicação. Isso porque o tempo de espera para a primeira consulta em psiquiatria era em torno de três meses, pois o CAPS tinha uma demanda muito grande, atendendo até 2016 uma região de quase dois milhões de habitantes.

Nesse tempo de espera, as pessoas se inseriam no grupo de ouvidores de vozes e quando chegava a data da consulta muitos já consideravam que não era mais necessário. $E$, no grupo, além de conversar sobre o sofrimento e sobre as vozes, nos preocupava a questão do que ele ia fazer depois. ${ }^{2}$ Por isso, sempre buscávamos articular estratégias de inserção social, para a pessoa não ficar dependente do serviço, para não institucionalizar como manicômio, ou seja, virar um "CAPScômio". Deste modo, tivemos pessoas que arrumaram emprego, voltaram a estudar, e já estavam bem e por isso não precisaram ir na primeira consulta psiquiátrica.

Ainda em 2015 decidimos criar, por iniciativa deles, o grupo virtual. Isso pensando nas demandas que ocorrem após as dezoitos horas, período em que o CAPS II está fechado, e pelo fato das pessoas não desejarem ir para o manicômio, devido a torturas que sofreram lá. E, embora em Brasília houvesse um CAPS III para situações de emergência, de crise, este tinha poucas vagas e, infelizmente, funcionava numa lógica semelhante à do manicômio. Por isso, pensamos o canal virtual do aplicativo WhatsApp, pois às vezes com uma ligação já é possível acalmar a pessoa. E a nossa experiência demonstra isso, pois já conseguimos prevenir crise por mensagem. 


\section{JOURNALOF \\ HEALTH \\ ISSN 2236 - 1987}

Atualmente, temos três grupos virtuais, um que é só de ouvidores de vozes, um que são esses mesmos ouvidores e outras pessoas que fazem uso do sistema de saúde mental e um de familiares, que sentiram necessidade de conversar sobre questões deles, como dificuldades que eles têm. A gente tem mais de dez ouvidores de vozes nesses grupos, e nos de familiares temos mais de vinte $e$ cinco participantes. Então o canal virtual tem se mostrado um recurso interessante.

Continuamos com o grupo virtual, mas em janeiro de 2017, sentimos necessidade de continuar o grupo presencial. Isso porque algumas pessoas começaram a receber alta do CAPS e foram referenciadas para outros grupos, $e$ o grupo de ouvidores de vozes do CAPS havia terminado, pois nenhum profissional deu continuidade. Neste momento, dois familiares me ligaram $e$ falaram assim "olha, meu filho e minha mãe não estão bem e eu acho que eles estão sentindo falta do grupo". Daí em março retomamos, só que com uma perspectiva diferente, pois o grupo foi para a comunidade.

Hoje temos a perspectiva de oficialização de uma Organização não governamental - ONG, que se chama "Instituto Mãos Amigas". Além de um trabalho de garantia de direitos que é feito família a família, temos: um grupo de ouvidores de vozes que é realizado de 15 em 15 dias (às sextas-feiras pela manhã), no Centro Comunitário da Prefeitura da comunidade; e um outro grupo de ajuda mútua, que acontece duas vezes por mês, aos sábados de tarde, para que as pessoas, principalmente os familiares que trabalham durante a semana, possam participar. O de ajuda mútua é realizado nas casas dos familiares ou frequentadores dos serviços de saúde mental, e de modo itinerante (o grupo decide de acordo com a necessidade das pessoas), e também conta com a participação de ouvidores de vozes.

A necessidade desses espaços se deu devido a relatos de alguns familiares e de ouvidores de vozes que expressavam a exclusão que sofriam: "olha, eu fim de semana a família me exclui, eu não tenho para onde ir, então eu gostaria que a gente se reunisse num lugar para poder fazer uma confraternização, eu não saio para dançar, não me deixam sair". Então passamos a fazer os grupos nesses locais e estamos intercalando as atividades desenvolvidas. Eles estão se reunindo para fazer atividade física também e estamos analisando outras atividades que podem ser feitas como artesanato, tecelagem, confecção de alimentos que eles gostam de fazer, e reciclagem, por exemplo.

Em relação as dificuldades, estas foram mais presentes com pessoas que tinham uma longa carreira de internação, de reinternação e de uso de medicação, que acredito que geram perdas. No entanto, mesmo assim conseguimos fazer com que eles pudessem ter uma qualidade de vida um pouco melhor daquela que tinham. Então, a partir da articulação que fizemos com os familiares e as redes de garantia de direitos, como o Instituto Nacional de Seguridade Social (INSS), Defensoria Pública, Ministério Público, da Lei Maria da Penha, conseguimos 
responder a casos de violência que atendemos. Isso porque ao trabalhar o conteúdo das vozes, estas acabavam trazendo questões do contexto de vida ${ }^{1}$, que não eram consideradas numa abordagem tradicional que trabalha na perspectiva da doença. Então, em relação a violência, conseguimos acessar o Ministério Público e a rede, para que algumas mulheres pudessem começar a pensar na questão da emancipação, de sair dessas relações.

Neste sentido, muitas pessoas que se identificaram com o grupo, teve relatos de pessoas que pela primeira vez se sentiam fazendo parte de um grupo, que se sentiam compreendidas. Desta forma, tivemos experiências de alta com curto tempo de intervenção, pessoas com três ou quatro meses de acompanhamento. Tivemos também o ganho de autonomia na hora da consulta com o profissional da psiquiatria, da pessoa conseguir relatar que não estava se sentindo bem com determinada medicação e por isso solicitar a troca. A experiência no grupo, com pessoas que tomam a mesma medicação, ou que já tomaram e essa troca de experiência tem permitido esse diálogo com $o$ profissional de psiquiatria que era uma das maiores limitações que eles relatavam, até então.

\section{O grupo e a relação com a comunidade}

0 "Ouvir vozes" tem pessoas da comunidade que querem saber sobre o sofrimento, familiares, enfim, vizinhos. Então desde março de 2017 estamos desenvolvendo os grupos de ouvidores de vozes na comunidade. Isso porque acreditamos que sem envolver a comunidade não é possível transformar a cultura.

O grande problema que eu percebo na minha experiência é o medo que os ouvidores possuem sobre como serão recebidos no trabalho ou na faculdade por pessoas que não tem contato com essas questões do diagnóstico, ou de 'ouvir vozes'. Portanto, é fundamental ir para a comunidade e estender esse conhecimento, e promover o contato com quem escuta vozes ou com quem tem algum tipo de sofrimento psíquico ${ }^{2}$. Somente a partir do diálogo é possível se colocar no lugar do outro e buscar entender outras dimensões que são da vida.

Então, ir para a comunidade ajuda a transformar. Essa tem sido nossa experiência com esse grupo na comunidade e tenho visto muitos efeitos positivos, nas relações com a família, os amigos e vizinhança. Antes as pessoas iam para o CAPS e ficavam um tempo lá e depois voltavam para a comunidade. Hoje realizamos o trabalho na comunidade $e$ estamos sentindo que $o$ movimento está mais fluído, a partir do envolvimento de familiares e pessoas da comunidade que tenham interesse em saber o que é saúde mental, o que é o sofrimento.

Esses grupos na comunidade têm como facilitador um familiar que é responsável pelo grupo de familiares, e seus filhos, são responsáveis pelo grupo 
de ouvidores de vozes. E é muito interessante como o cuidado vai se desenvolvendo a partir da postura dos facilitadores, então hoje em dia as pessoas formadas nas referidas áreas não precisam ficar nessa função, eu não preciso ficar nessa função. Porque eles mesmos conduzem, perguntam e fazem intervenções, que inclusive eu, pelo menos, nunca tinha pensado na vida.

O grupo de ajuda mútua, como já foi falado, é realizado de forma itinerante, na casa de pessoas ligadas ao projeto, mas já teve um lugar fixo (uma casa de eventos) que, por questões burocráticas, não pode nos receber mais. $E$ a Facilitadora se envolveu nesse trabalho de ajuda mútua e ouvidores de vozes em função do filho ter recebido um diagnóstico em um momento pessoal bem difícil, e ter precisado fazer tratamento no CAPS. À época o prognóstico dele era ruim. E hoje ele está na faculdade realizando o sonho dele e ajudando outras pessoas também na condução do grupo. E foi a partir dos efeitos que o grupo produziu na vida do filho, que esse familiar passou a trabalhar na articulação com as pessoas que saem do hospital. Então temos o contato com uma psiquiatra que acolhe demandas de pessoas que pedem o suporte do grupo.

A facilitadora do grupo de familiares também vai em diversos órgãos públicos (INSS, Defensoria Pública, etc) fazendo um trabalho de acompanhamento terapêutico. Com esse trabalho ela tem conhecido diversas pessoas e consegue manter um contato quase diário com elas o que nos ajuda a manter a participação no grupo.

Quanto à participação nos grupos, nosso objetivo era ter trinta integrantes pelo menos, e temos aproximadamente quarenta pessoas inscritas no projeto. No grupo de ajuda mútua a participação tem sido em média 25 pessoas, entre pessoas em sofrimento (considerando ouvidores de vozes) e familiares; e no grupo de ouvidores de vozes a média tem sido de dez (entre ouvidores $e$ familiares) - apesar de a maioria das pessoas em sofrimento cadastradas no projeto ser de ouvidores de vozes, poucos deles têm a disponibilidade para participar às sextas-feiras.

Consideramos um número bom e queremos expandir para outras regiões também. Porém, primeiro precisamos consolidar esses grupos lá na Ceilândia, para depois iniciar em outra região, visando estender o trabalho e tornar ele mais potente.

\section{REFERÊNCIAS}

1 Kantorski LP, Antonacci MH, Andrade APM, Cardano M, Minelli M. Grupos de ouvidores de vozes: estratégias e enfrentamentos. Saúde debate [Internet]. 2017[acesso em 05 maio 2018];41(115):1143-55. Disponível em: http:/ / www.scielo.br/scielo.php?script=sci_arttext\&pid=S0103$11042017000401143 \& \operatorname{lng}=e n \& n r m=i s o$ 
2 Kantorski LP, Andrade APM, Cardano M. Estratégias, expertise e experiências de ouvir vozes: entrevista com Cristina Contini. Interface [Internet]. 2017 [acesso em 05 maio 2018];21(63):1039-48.

Disponível

em:

http: / / www.scielo.br/scielo.php?script=sci_arttext\&pid=S1414-

$32832017000401039 \& \operatorname{lng}=e n \& n r m=i s o$

Data de publicação: 19/09/2018 